\title{
Cerebral Palsy in Children: Evaluation of Clinical Outcomes
}

\author{
Silvia Marino ${ }^{1}$, Luca Sabino ${ }^{1}$, Raffaele Falsaperla ${ }^{1}$, Annamaria Sapuppo ${ }^{2}$, Tiziana Timpanaro ${ }^{2}$, Carmela \\ Massimino², Federica Sullo², Alessandra Fontana ${ }^{2}$, Valeria Venti ${ }^{2}$, Anna Portale ${ }^{2}$, Martina Caccamo ${ }^{2}$, \\ Marina Mazzurco² and Piero Pavone ${ }^{2 *}$ \\ ${ }^{1}$ UO di Neonatologia e Pediatria, Italy \\ ${ }^{2}$ UO di Pediatria, AUO OVE-Policlinico, Italy \\ *Corresponding author: Piero Pavone, UO di Pediatria, AUO OVE-Policlinico, University of Catania, Catania, Italy
}

\section{ARTICLE INFO}

Received: 幽 November 25, 2019

Published: 幽 December 02, 2019

Citation: Silvia Marino, Luca Sabino, Raffaele Falsaperla, Annamaria Sapuppo, Tiziana Timpanaro, et al. Cerebral Palsy in Children: Evaluation of Clinical Outcomes. Biomed J Sci \& Tech Res 23(3)-2019. BJSTR. MS.ID.003898.

\section{ABSTRACT}

During the period of January 2015 and January 2018 we have screened over 11,280 neonates born in both the hospitals in Catania, in this study we do not entered premature children (less than 35 week of gestation). We found the incidence of CP in 48 children (4\%), 19 males and 29 females. Of them several 14 (29\%) children have a severe form of CP, $16(33 \%)$ a mild-moderate and $18(38 \%)$ light. In all children the ultrasonography shows various degree of PVL and IVH according to the criteria of Papile et al 1978. EEG findings, clinical presentation of seizures, brain MRI and rehabilitations programs were studied.

Keywords: Cerebral Palsy; Childhood; ultrasonography; Brain RMN

\section{Short Communication}

Cerebral palsy (CP) is a disorder of movement, muscle tone or posture that is caused by an insult to the immature, developing brain, during the pregnancy most often before birth. The actual definition of CP, established in 2007 defines CP as "a group of permanent disorders of the development of movement and posture, causing activity limitation, that are attributed to non-progressive disturbances that occurred in the developing fetal or infant brain" [1]. Despite over the past 15 years knowledge about diagnosis, treatment and prevention of this disorder have considerably improved, it still remains one of the most common diseases in industrialized countries and the most common cause of neuromotor disability in childhood, [2] affecting about 1 in 500 neonates with an estimated prevalence of 17 million people worldwide [3]. The incidence remains constant around 2 children for thousand per years [4]. One of the hallmarks of cerebral palsy is its variability. In determining health and social outcomes in children affected from cerebral palsy (CP) several possible factors are involved, including the underlying cause, the severity of the clinical scenario of $\mathrm{CP}$, medical interventions, and the environment surrounding the child. Several formal methods of classifying persons with $\mathrm{CP}$, such as the
Gross Motor Function Classification System, have been developed to standardize that variability [5].

Characteristic signs and symptoms are usually better recognizable during infancy or preschool years (around 3-5 years), despite may be present already in early infancy. In general, cerebral palsy can cause an impairment in motor functions with altered movement associated with exaggerated reflexes, floppiness or rigidity of the limbs and trunk, abnormal posture, involuntary movements, unsteadiness of walking, or some combination of these. Precocious signs can be represented by neurobehavioral alterations (lethargy, irritability, difficult to handle and poor visual attention), or alteration in developmental reflexes (exaggeration, delay in disappearance) [6]. People with cerebral palsy may have difficulty with swallowing and commonly have eye muscle imbalance. People with cerebral palsy may have reduced range of motion at various joints of their bodies due to muscle stiffness.

The predominant CP phenotypes [7] are included in three syndromes: Spastic CP, with upper neuron signs as spasticity, extensor plantar response, or hyperreflexia, to which belong 
Diplegic, Hemiplegic and Quadriplegic subtypes, basing on topographic distribution; Ataxic CP with cerebellar involvement as progressive ataxia and language and motor impairment; Dyskinetic $\mathrm{CP}$ with several pattern of involuntary movements, sub-classifiable in Chorea-Athetoid CP and Dystonic CP. It can be observed also combined forms, defined Mixed CP.

Previously considered, Hypotonic CP has been excluded from current classification, since children with hypotonic attitude in infancy later develop a predominant phenotype belonging to the three main above-mentioned syndromes. Moreover, some children can present comorbidities as epilepsy, cognitive and sensory impairment or altered growth [8]. Only a multidisciplinary approach and the development of targeted therapeutic strategies and shared by the various specialists involved can help improve the quality of life of these children.

Based on the clinical symptoms and outcome we distinguish three different form of CP: light, mild/moderate and severe. Severe cases of Cerebral Palsy can lead to early death in newborns, babies, infants, and toddlers. Of special concern for risk of premature death are children who experience severe spasticity, and children with quadriplegia or quadriparesis. Those ones who presented neonatal jaundice are also at risk. Many cases of infant mortality are related to premature birth and very low birth weight. Studies are being performed to ascertain whether the brain damage leads to premature birth and low birth weight, or whether the reverse leads to the brain damage. In these situations, though, the injury to the brain or other organs may be too great to sustain life [9]. Severity of impairment is significant when it influences mobility, feeding, and cognitive functioning. Severe impairment can lead to other conditions. For example, severe spasticity in limbs can lead to contracture and frozen joints. Severe impairment often increases a child's dependency on others; he or she may require 24-hours care and monitoring. The inability to be independent, provide self-care, and be mobile is thought to contribute to quality of life issues and life span, but not in all cases. Those with severe impairment can lead healthy lives well into adulthood.

The effect of cerebral palsy on functional abilities varies greatly. Some people can walk while others aren't able to walk. Some people show normal to near normal intellectual function, but others may have intellectual disabilities. Epilepsy, blindness or deafness also may be present. Both children and adults with CP must contend with increased mortality as well as many secondary conditions that can influence activities and participation in society. Predicting outcomes for children with $\mathrm{CP}$, establishing realistic goals, and determining the best interventions to improve functioning are all facilitated by applying research results to individual decisions. In order to employ the best available measurements, several other studies are needed, especially those performed with large representative samples. In addition, to define a more precise prognostic evaluation the childhood factors affecting outcomes in adults with CP still need to be elucidated.
A study conducted in 2014 by A. Ferrari and other [10] has defined 6 signs suggestive of perceptual disturbances in children with cerebral palsy. These signs include startle response, startle upper limbs in position, frequent eye blinking, the freezing posture, the look of the averted eyes, grimace. The semiotics of perceptual disturbances may be used as a specific and sensitive tool to identify a new class of patients within heterogeneous clinical types of bilateral cerebral palsy and could help doctors identify the prognosis of motor disorders presented by these children. Infant cerebral palsy covers the broadest spectrum of disorders of posture and movement of childhood. The wide range of problems associated with ICP poses difficulties in patient assessment and in achieving the objectives of rehabilitation. Another study conducted in 2015 by İçağasığlu [11] confirmed as a prolonged rehabilitation treatment (24 months) significantly better treatment outcome of mild and moderate forms of the PC as shown in the increase of the score WeeFIM post-treatment compared to baseline. In this review we have evaluated the incidence of this disease in two tertiary hospital of Catania, Italy. (Hospital Santo Bambino and Policlinic University Hospital Catania),

\section{Materials and Methods}

a. During the period of January 2015 and January 2018 we have screened over 11,280 neonates born in both the hospitals in Catania, in this study we do not entered premature children (less than 35 week of gestation).

b. We found the incidence of CP in 48 children (4\%), 19 males and 29 females. All children underwear to brain ultrasonography, EEG, a combination of neurological (Hammersmith Neonatal Neurologic examination), neuromotor (GENERAL MOVEMENTS, test of infant motor PERFORMANCE, BAYLEY SCALES), neurobehavioral (Nicu network neurobehavioral scale-Preemie-Neuro), Brain MRI, followed up every 3 months for 24 months.

c. Several $14(29 \%)$ children have a severe form of CP, 16 (33\%) a mild-moderate and 18 (38\%) light. In all children the ultrasonography shows various degree of PVL and IVH according to the criteria of Papile et al. [12].

d. EEG findings demonstrate in 20 cases slowing in the centrotemporal left derivation and in 5 cases the presence of spike and polis pike in the right parieto-frontal region with tendency at the diffusion. Seizures have been documented in 8 cases, of which in 6 cases there were tonic-clinic seizures, and partial in 2 cases. In 6 of these 8, seizures surveys were associated to a severe form of $\mathrm{CP}$.

e. Brain MRI shows enlargement of the lateral ventricular in $34 / 48$ of the cases with mild asymmetric in all the patient.

f. All These children underwent to a prolonged rehabilitation treatment (24 months) that significantly improved the outcome of light and mild-moderate forms of the CP. 


\section{Conclusion}

In conclusion the outcome of children with $\mathrm{CP}$ is difficult to predict because is related to etiological cause of the $\mathrm{CP}$ and to intrinsically factor of the children. For the future it is hoped to be able to conduct more homogeneous (for example rehabilitations treatment there are not homogenous) studies to be able to adapt the observed results, uniformly to all children with CP.

\section{References}

1. (2007) The Definition and Classification of Cerebral Palsy. Dev Med Child Neurol 49: 1-44.

2. Reddihough DS, Collins KJ (2003) The epidemiology and causes of cerebral palsy. Aust J Physiother 49(1): 7-12.

3. Graham HK, Rosenbaum P, Paneth N, Dan B, Lin JP, et al. (2016) Cerebral palsy. Nat Rev Dis Primers 7(2): 15082.

4. Flett PJ (2003) Rehabilitation of spasticity and related problems in childhood cerebral palsy. J Paediatr Child Health 39(1): 6-14.

5. Mccormick A (2017) The Gross Motor Function Classification System: 20 years on. Dev Med Child Neurol 59(6): 571.

\section{ISSN: 2574-1241}

DOI: 10.26717/BJSTR.2019.23.003898

Piero Pavone. Biomed J Sci \& Tech Res

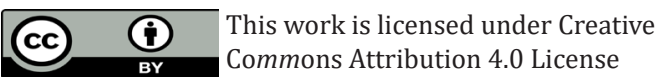

Submission Link: https://biomedres.us/submit-manuscript.php
6. Noritz GH, Murphy NA (2013) Neuromotor Screening Expert Panel Motor delays: early identification and evaluation. Pediatrics 131(6): e2016-27.

7. Gulati S, Sondhi V (2018) Cerebral Palsy: An Overview. Indian J Pediatr 85(11): 1006-1016.

8. Novak I, Hines M, Goldsmith S, Barclay R (2012) Clinical prognostic messages from a systematic review on cerebral palsy. Pediatrics 130(5): e1285-312.

9. Linsell L, Malouf R, Morris J, Kurinczuk JJ, Marlow N, et al. (2016) Prognostic factors for cerebral palsy and motor impairment in children born very preterm or very low birthweight: a systematic review. Dev Med Child Neurol 58(6): 554-69.

10. Ferrari A, Sghedoni A, Alboresi S, Pedroni E, Lombardi F, et al. (2014) New definitions of 6 clinical signs of perceptual disorder in children with cerebral palsy: an observational study through reliability measures. Eur J Phys Rehabil Med 50(6): 709-716.

11. İçağasıoğlu A, Mesci E, Yumusakhuylu Y, Turgut ST, Murat S, et al. (2015) Rehabilitation outcomes in children with cerebral palsy during a 2-year period. J Phys Ther Sci 27(10): 3211-3214

12. Papile LA, Burstein J, Burstein R, Koffler H (1978) Incidence and evolution of subependymal and intraventricular hemorrhage: a study of infants with birth weights less than 1,500 gm. J Pediatr 92(4): 529-534.

$\begin{array}{ll}\text { BIOMEDICAL } & \text { Assets of Publishing with us } \\ \text { RESEARCHES } & \text { - Global archiving of articles } \\ & \text { - Immediate, unrestricted online access } \\ \end{array}$

